\title{
Behaviour of steel prestressing wires under extreme conditions of strain rate and temperature
}

\begin{abstract}
The purpose of this paper is to provide information on the behaviour of steel prestressing wires under likely conditions that could be expected during a fire or impact loads. Four loadings were investigated: a) the influence of strain rate - from $10^{-3}$ to $600 \mathrm{~s}^{-1}$ at room temperature, $b$ ) the influence of temperature - from 24 to $600^{\circ} \mathrm{C}$ - at low strain rate, c) the influence of the joint effect of strain rate and temperature, and d) damage after three plausible fire scenarios.

At room temperature it was found that using static values is a safe option. At high temperatures our results are in agreement with design codes (see Fig. 3). Regarding the joint effect of temperature and strain rate, mechanical properties decrease with increasing temperature, although for a given temperature, yield stress and tensile strength increase with strain rate. The data provided can be used profitably to model the mechanical behaviour of steel wires under different scenarios.
\end{abstract}

Keywords: prestressing steel, high strain rate, high temperature, impact loads

\section{Introduction}

There is a growing interest in modelling the response of prestressed concrete structures subjected to impact loads, fires or explosive detonations. The complexity of such buildings, together $w^{i t h}$ the nosd to couple phenomena usually considered in ssoration, forces compromises in methodology not required for simple fire scenarios or impact loads alone.

Until recently, the straightforward approach was to test a model structure or component under suitable thermomechanical loads and infer information from the data recorded. With the advent of powerful computers, numerical modelling of complex structures has become feasible and fire or impact scenarios have been tackled.

A basic ingredient for numerical modelling is the constitutive equations of the material components, particularly their performance under extreme conditions of strain rate and temperature. The purpose of this paper is to provide information on the behaviour of steel wires used for prestressed concrete under the aforementioned loads.

\footnotetext{
* Corresponding author: melices@mater.upm.es
}

To the authors' knowledge, whereas little data is available on this subject, the following are the main studies carried out:

Nakkalil et al. [1] performed compression tests at high temperatures and strain rates with eutectoid steel cylinders. Itabashi and Kawata [2] conducted tensile tests on carbon steels (carbon content mn nge $0.14-0.54 \%$ by wt.) and found that the yield stress and ultimate strength could be predicted by an empirical formula for quasi-static tensile tests, taking into consideration carbon and manganese contents. Later, $\mathrm{He}$ et al. [3] carried out compression tests with eutectoid steel wires at high strain rates to provide data for the numerical modelling of the processing of wires fabricated under high-speed cold-drawing conditions. More recently, Rohr et al. [4] presented the results of a research programme aimed at describing the behaviour of a high-strength steel alloy (35 NiCrMoV109) over a wide range of stain rates for numerical simulations of dynamic events and developed a phenomenological material model for this purpose. More recently, the influence of temperature on the performance of steel wires for prestressing was reported in a paper published by Atienza et al. [5].

Although significant progress has been made in the development of material constitutive models, the physical models are still not advanced enough to account for the whole complexity of the dynamic response of cold-drawn eutectoid steel wires. Nevertheless, the interested reader is advised to consult a classical paper by Johnson and Cook [6], or a more recent update [7] devoted to high-strength steels, where a modified Johnson-Cook model was developed to describe the relationship between flow stress, strain rate and temperature over a wide range of temperatures and loading rates.

Data from codes and design recommendations is likewise scarce. In CEB Bulletin 187 [8] it is reported that some mechanical properties - such as yield stress and tensile strength - show a linear increase behaviour when drawn as a function of the logarithm of strain rate, especially for hot-rolled reinforcing steel, cold-worked reinforcing steel and mild steel. Interestingly, it is pointed out that for prestressing wires there is practically no influence on strain rate. In the present draft of the Model Code [9] it is stated that "the tensile properties of prestressing steel increase with speed or rate of strain application", without proposing any specific values or presenting additional information. 
Therefore, the purpose of this paper is to provide data on the behaviour of prestressing steel under likely conditions that could be expected during a fire or impact loads. To this end, the following loadings were explored:

a) Influence of strain rate - ranging from $10^{-3}$ to $600 \mathrm{~s}^{-1}$ at room temperature $\left(T=24^{\circ} \mathrm{C}\right)$. This strain rate interval covers six orders of magnitude: from static loading $\left(10^{-3} \mathrm{~s}^{-1}\right)$ or seismic actions of about 1 to $10 \mathrm{~s}^{-1}$ to impact range (vehicle collision and structural crash) or explosive loads $\left(10^{2} \mathrm{~s}^{-1}\right.$ or higher) $[10,11]$.

b) Influence of temperature - ranging from 24 to $600{ }^{\circ} \mathrm{C}$ at low strain rate $\left(\dot{\varepsilon}=10^{-3} \mathrm{~s}^{-1}\right)$. This temperature range allows management under foreseeable fire scenarios $[12,13]$. Above $600{ }^{\circ} \mathrm{C}$ it is assumed that the steel wires are not in service due to a sharp fall in strength.

c) Influence of the joint effect of strain rate and temperature because both phenomena are generally combined under extreme conditions such as impact loads, fire or explosions.

d) Results from three plausible fire scenarios. The aim of these examples is to characterize the mechanical behaviour of steel wires at room temperature after a simulated fire, particularly when the tendons are loaded at different strain rates. After a fire, an assessment of the residual loadbearing capacity of the structure has to be carried out to decide if it is still possible to use it, even if it seems that no repairs are needed. Appropriate knowledge of the behaviour of construction materials after a fire is of major importance for answering this question.

It is hoped that this data will provide useful inputs for designers when performing numerical modelling of prestressed concrete components under fire or impact loadings.

\section{Materials and methods \\ 2.1 Materials}

A commercially available steel wire for prestressed concrete was used for this research. The chemical composition was (\% by wt.): $0.815 \mathrm{C}, 0.231 \mathrm{Si}, 0.642 \mathrm{Mn}, 0.012 \mathrm{P}$, $0.008 \mathrm{~S}, 0.044 \mathrm{~V}$ and $0.221 \mathrm{Cr}(\mathrm{C}=$ carbon, $\mathrm{Si}=$ silicon, $\mathrm{Mn}$ $=$ manganese, $\mathrm{P}=$ phosphorus, $\mathrm{S}=$ sulphur, $\mathrm{V}=$ vanadium, $\mathrm{Cr}=$ chromium).

The manufacture proceeded according to the following steps: rods of $12 \mathrm{~mm}$ diameter were subjected to six drawing passes to reach a final diameter of $7.0 \mathrm{~mm}$, thus the accumulated true strain was 1.08 . The drawing velocity was $44 \mathrm{~m} / \mathrm{min}$ and the temperature, which was controlled during the process, reached a maximum value of $197^{\circ} \mathrm{C}$ on the surface of the wire at the exit of the last die. After drawing, they were subjected to an industrial thermomechanical stress-relieving treatment: steel wires were heated to $400{ }^{\circ} \mathrm{C}$ and stressed to $64 \%$ of their maximum stress $\sigma_{\max }$ for 2 or $3 \mathrm{~s}$.

The wire microstructure is fully pearlitic because it corresponds to the eutectoid point $(0.8 \% \mathrm{C})$, with alternating nanosize ferrite $(\alpha \mathrm{Fe})$ and cementite $\left(\mathrm{Fe}_{3} \mathrm{C}\right)$ lamellae (interlamellar spacing approx. $100 \mathrm{~nm}$ ). This is typical of cold-drawn eutectoid steel, with the lamellae being aligned in the drawing direction, which coincides with the wire axis.

\subsection{Mechanical tests \\ 2.2.1 Low and medium strain rate tests at different temperatures}

Tensile tests were performed with an Instron 8803 tensile testing machine with a load cell of $100 \mathrm{kN}$ and load versus strain being continuously recorded.

Low strain rate tests were performed at a strain rate of $\dot{\varepsilon}=10^{-3} \mathrm{~s}^{-1}$, medium strain rate tests at $\dot{\varepsilon}=1 \mathrm{~s}^{-1}$.

High-temperature tests were performed using a furnace with the temperature controlled to $\pm 2.5^{\circ} \mathrm{C}$. Temperature control was achieved using a K-thermocouple directly attached to the specimen. A digital image correlation system from LIMESS Messtechnik was used for measuring the strain. Specimens were painted using two different temperature-resistant paints to deposit a dot matrix on its surface. Tracking the displacements of these points gave the specimen strains using the proper software. The furnace used had two observation windows, which allowed the specimens to be monitored during testing. A Nikon video camera was used for the low strain rate tests, which acquired images at $1 \mathrm{~s}$ intervals, whereas at medium strain rates a Phantom v12.1 high-speed camera was used, recording at $6000 \mathrm{fps}$. Fig. 1 shows the testing machine, furnace and high temperature video extensometer system.

Load and strain histories were measured during the tests. From these results, the full stress-strain curve was computed, measuring the yield strength, the maximum load, the deformation under maximum load and the deformation at rupture. At least two tests were performed in each condition. Due to the very short duration of the medium strain rate tests at $1 \mathrm{~s}^{-1}$ and some problems with the painting, it was not possible to obtain the strain results on some of the tests. It should be pointed out that these strain rates are the maximum that static testing machines can perform because they are forced to work at the limits of their loading rate range.

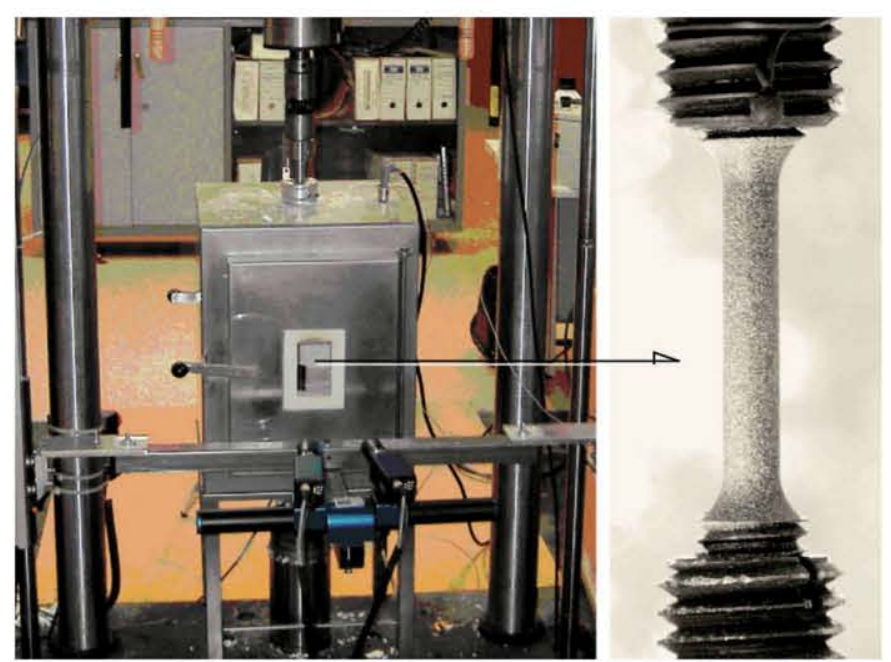

Fig. 1. Setup for low and medium strain rate tests at different temperatures and a close-up view of a steel sample with painted dots 


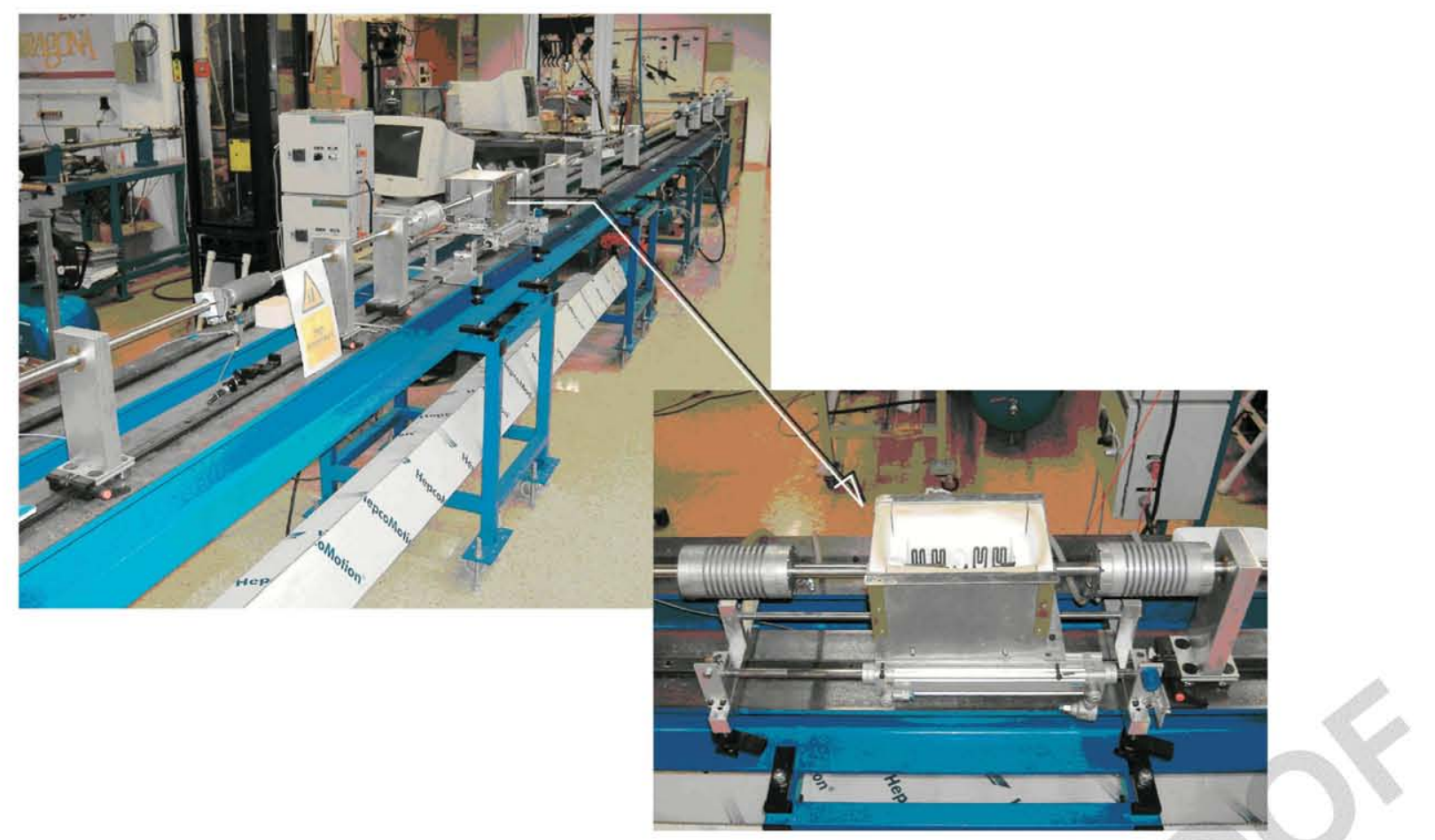

Fig. 2. Setup for high strain rate tests at different temperatures and a close-up view of the furnace

\subsubsection{High strain rate tensile tests at different temperatures}

Different testing techniques have to be employed at higher strain rates. The widely used Split Hopkinson Tension Bar (SHTB) technique was used in this work to obtain the stress-strain curve at strain rates in the order of $10^{3} \mathrm{~s}^{-1}$. General descriptions of the SHTB technique are given elsewhere, see, for example, Zukas et al. [10].

High strain rate tests were performed using a special Hopkinson device designed for testing at high temperatures [12], which consisted of a projectile, incident and transmitter bar, and associated instrumentation for recording data. The device used was a $12 \mathrm{~m}$ Hopkinson bar (Fig. 2). Loads were generated by a $2000 \mathrm{~mm}$ long tubular projectile impacting against a $4000 \mathrm{~mm}$ steel bar inside a gun using compressed air. The load was transmitted to two Inconel bars with a length of $3850 \mathrm{~mm}$ and diameter of $19 \mathrm{~mm}$. The tensile specimen was attached by screwing between the two bars, and placed inside a furnace. The bars were cooled using a cooling water system. This device enables an adiabatic stress-strain curve to be obtained using the measurements of the deformation of the Inconel bars. The specimen geometry was the same as that for static tests.

\section{Results and discussion}

\subsection{Influence of strain rate at room temperature}

Experimental results show a small increase in the recorded values as the loading rate increases.

Table 1 summarizes the average values of yield stress $\sigma_{y}$, maximum stress $\sigma_{m}$, strain at maximum stress $\varepsilon_{m}$ and rupture strain $\varepsilon_{r}$ for the steel wires used in this research.

In this experiment, the range of loading speed is nearly six orders of magnitude (from $10^{-3}$ to $660 \mathrm{~s}^{-1}$ ) and
Table 1. Influence of strain rate at room temperature $\left(T=24^{\circ} \mathrm{C}\right)$

\begin{tabular}{lllll}
\hline Strain rate & $\sigma_{y}(\mathbf{M P a})$ & $\sigma_{\max }(\mathbf{M P a})$ & $\varepsilon_{\max }(\%)$ & $\varepsilon_{\boldsymbol{r}}(\%)$ \\
\hline $10^{-3} \mathrm{~s}^{-1}$ & 1500 & 1856 & 4.7 & 7.0 \\
$1 \mathrm{~s}^{-1}$ & 1610 & 1860 & - & - \\
$660 \mathrm{~s}^{-1}$ & 1696 & 2069 & 5.2 & 8.4 \\
\hline
\end{tabular}

the increases in yield stress and maximum load are 13 and $11 \%$ respectively. Considering an increase in such values of about $10 \%$ - the usual approach - is a safe assumption.

It should be pointed out that low strain rates are isothermal tests, whereas medium and high strain rate tests can be considered as adiabatic. This implies that, during specimen deformation, the temperature increases due to thermal work because the specimen has no time to exchange heat with the environment. This produces a temperature increment in the specimen as deformation increases which can be computed using the Taylor-Quinney equation [11]. For this type of steel, a linear temperature increase with a deformation of $5{ }^{\circ} \mathrm{C}$ per $1 \%$ increase in strain can be assumed.

Values of Young's modulus are difficult to measure during very high strain rates. For very low $\left(10^{-3} \mathrm{~s}^{-1}\right)$ and medium $\left(1 \mathrm{~s}^{-1}\right)$ strain rates, the recorded values are similar: $200 \mathrm{GPa}$. It is usually assumed that Young's Modulus remains unchanged when increasing strain rates. For tests performed at $660 \mathrm{~s}^{-1}$, the strain rate was not seen to have a significant influence on Young's Modulus.

Representative stress-strain curves at room temperature at low and high strain rates are shown in Fig. 3. Initial yielding at high strain rate is difficult to measure due to instabilities that appear as oscillations in the stress-strain diagram. Average values are shown as a dotted line. 


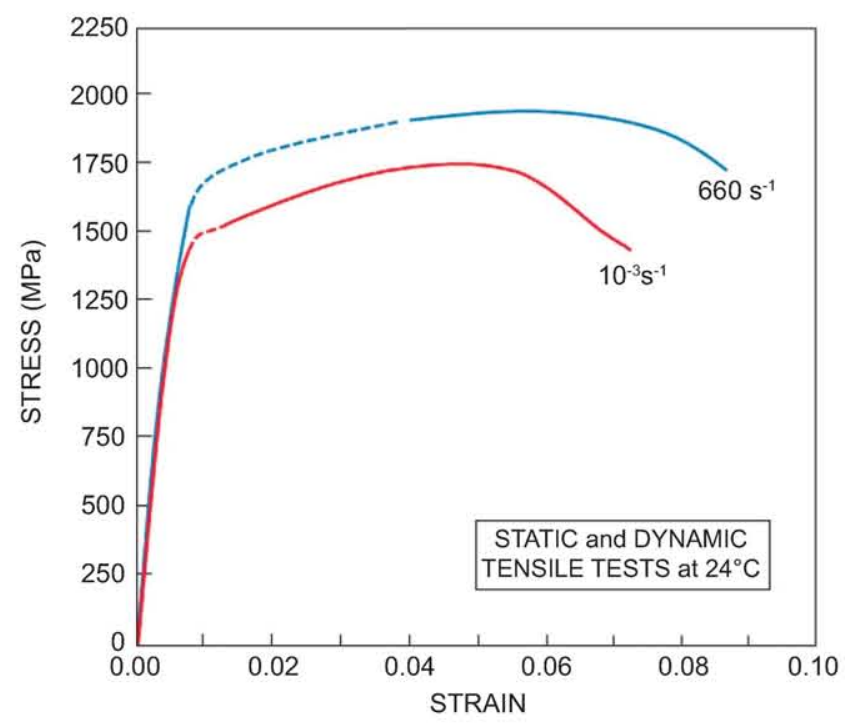

Fig. 3. Stress-strain curves (at room temperature) for low and high strain rates

\subsection{Influence of temperature}

Experimental results show a decrease in mechanical properties starting at $200^{\circ} \mathrm{C}$. For temperatures higher than $700{ }^{\circ} \mathrm{C}$ there is a sharp fall in the strength and noticeable changes in the microstructure that render the steel wires useless.

The measured average values of $\sigma_{y}, \sigma_{\max }, \varepsilon_{\max }$ and $\varepsilon_{r}$, together with values from another steel batch previously published in [5], are summarized in Table 2. Note that in this research, wires were kept for $2 \mathrm{~h}$ at the specified temperature and that wires from [5] were tested only after reaching the intended temperature. Moreover, wires from [5] were $5 \mathrm{~mm}$ in diameter (subjected to more drawing passes and hence with higher strain hardening); consequently, the two sets of results are not strictly comparable although the trend is similar.

These results lend additional support to recommended values from standards [13, 14], as shown in Fig. 4, where the relative strength (strength at temperature $T$ divided by strength at room temperature) as a function of temperature is drawn according to Eurocode and British Standard. Our experimental results fit quite well inside the suggested limits.

Regarding the initial Young's Modulus, no significant influence of the temperature was detected.

Stress-strain curves at low strain rate for different temperatures are shown in Fig. 5.

Table 2. Influence of temperature (tests at $\dot{\varepsilon}$

\begin{tabular}{lrrrrll}
\hline Test temperature & $\sigma_{y}(\mathbf{M P a})$ & \multicolumn{2}{c}{$\sigma_{\max }(\mathbf{M P a})$} & $\varepsilon_{\max }(\%)$ & $\varepsilon_{r}(\%)$ \\
\hline $24^{\circ} \mathrm{C}$ & 1500 & $1770 *$ & 1856 & $1950 *$ & 4.7 & 7.0 \\
$200^{\circ} \mathrm{C}$ & 1275 & $1472 *$ & 1675 & $1744^{*}$ & 5.4 & 12.3 \\
$400^{\circ} \mathrm{C}$ & 900 & $940^{*}$ & 983 & $1043 *$ & 2.6 & 17.8 \\
$600^{\circ} \mathrm{C}$ & 227 & $267^{*}$ & 256 & $270 *$ & 2.4 & 35.0 \\
\hline
\end{tabular}

* Tests from [5]

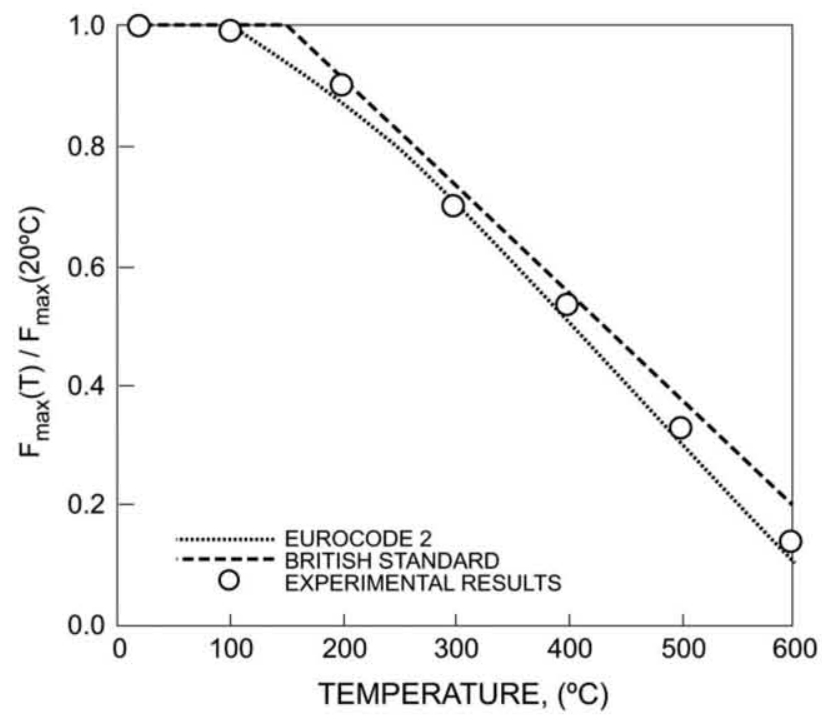

Fig. 4. Influence of temperature on the tensile strength of prestressing steel, in accordance with cited standards [13, 14], together with experimental results by the authors (this research); relative strength is defined as strength at a temperature $F_{\max }(T)$ divided by strength at room temperature $F_{\text {max }}\left(20^{\circ} \mathrm{C}\right)$

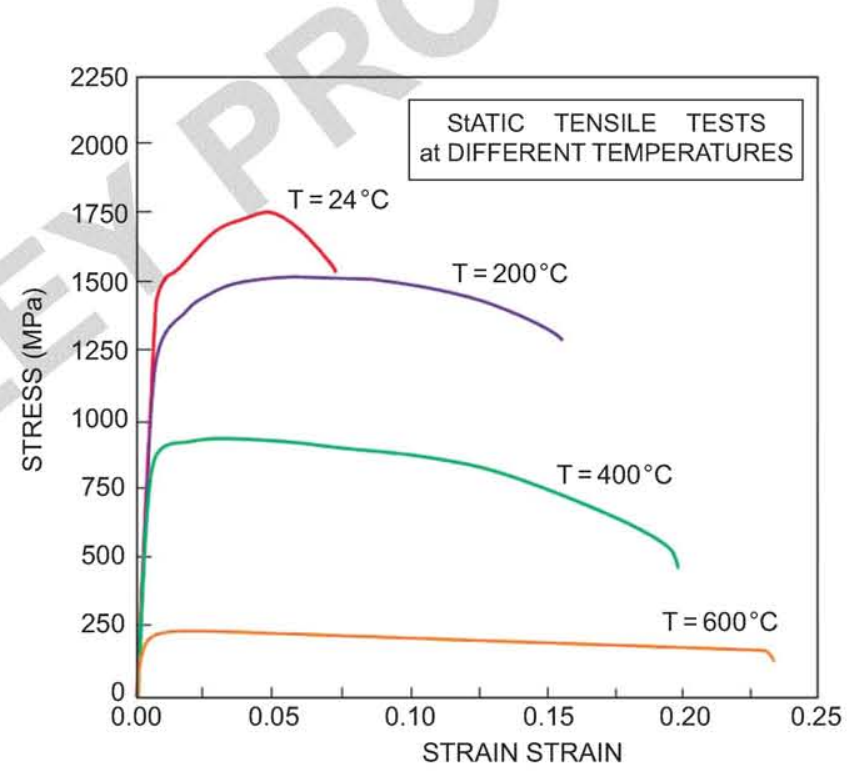

Fig. 5. Stress-strain curves (at low strain rate) for different temperatures

\subsection{Influence of strain rate and temperature}

Experimental results show a decrease in the mechanical properties as the test temperature increases, as expected from section 3.2, although for each temperature there is an increase in the mechanical properties (except for $\varepsilon_{r}$ ) when the strain rate increases.

Table 3 shows the average values for three selected temperatures $\left(200,400\right.$ and $\left.600{ }^{\circ} \mathrm{C}\right)$ and three strain rates $\left(10^{-3}, 1\right.$ and $\left.560 \mathrm{~s}^{-1}\right)$.

Fig. 6 shows the stress-strain curves at high strain rate for different temperatures. Note that the temperature effect is lower at high strain rate when compared with low strain rate curves. 
Table 3. Influence of temperature and strain rates

\begin{tabular}{|c|c|c|c|c|}
\hline \multicolumn{2}{|c|}{ Test conditions } & $\sigma_{y}(\mathrm{MPa})$ & $\sigma_{\max }(\mathrm{MPa})$ & $\varepsilon_{r}(\%)$ \\
\hline \multicolumn{5}{|c|}{ strain rate } \\
\hline & $10^{-3} \mathrm{~s}^{-1}$ & 1500 & 1856 & 7.0 \\
\hline \multirow[t]{2}{*}{$24^{\circ} \mathrm{C}$} & $1 \mathrm{~s}^{-1}$ & 1610 & 1860 & * \\
\hline & $660 \mathrm{~s}^{-1}$ & 1696 & 2069 & 8.0 \\
\hline \multicolumn{5}{|c|}{ strain rate } \\
\hline & $10^{-3} \mathrm{~s}^{-1}$ & 1275 & 1675 & 12.3 \\
\hline \multirow[t]{2}{*}{$200^{\circ} \mathrm{C}$} & $1 \mathrm{~s}^{-1}$ & 1325 & 1748 & 10.9 \\
\hline & $560 \mathrm{~s}^{-1}$ & 1488 & 1804 & 9.3 \\
\hline \multicolumn{5}{|c|}{ strain rate } \\
\hline & $10^{-3} \mathrm{~s}^{-1}$ & 900 & 983 & 17.7 \\
\hline \multirow[t]{2}{*}{$400^{\circ} \mathrm{C}$} & $1 \mathrm{~s}^{-1}$ & 1095 & 1365 & 16.6 \\
\hline & $560 \mathrm{~s}^{-1}$ & 1198 & 1497 & 8.8 \\
\hline \multicolumn{5}{|c|}{ strain rate } \\
\hline & $10^{-3} \mathrm{~s}^{-1}$ & 256 & 275 & 34.8 \\
\hline \multirow[t]{2}{*}{$600^{\circ} \mathrm{C}$} & $1 \mathrm{~s}^{-1}$ & 540 & 575 & $*$ \\
\hline & $560 \mathrm{~s}^{-1}$ & 776 & 935 & 16.6 \\
\hline
\end{tabular}

* not measured

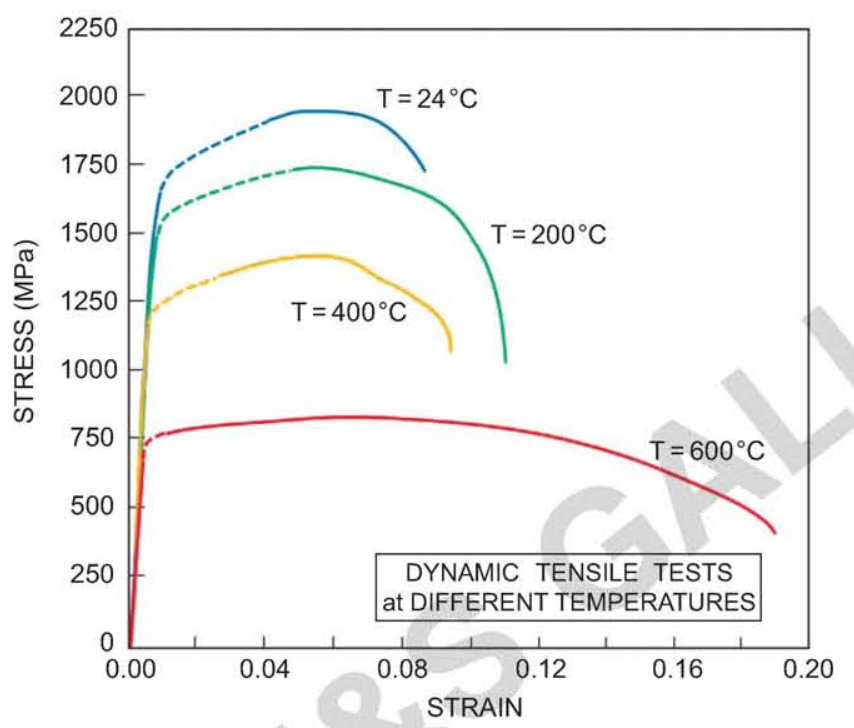

Fig. 6. Stress-strain curves (at high strain rate) for different temperatures

\subsection{Effect after a simulated fire: behaviour at $24^{\circ} \mathrm{C}$ and different strain rates}

To compute the behaviour of a prestressed concrete component in a fire, one of the inputs needed is the temperature-time curve of the prestressing steel. As concrete surrounds steel wires and has a low thermal conductivity, its thickness protects the steel wires, delaying their temperature rise. Standards [13-15] and recommendations [16-17] provide curves to predict the temperature inside concrete components under idealized fire conditions.

To simulate the effect of fire in this example, wires were subjected to a cycle of heating and cooling. The time-temperature curves used in this work, shown in Fig. 7, represent a realistic and conservative fire scenario. The effects of a fire will depend on its duration; in this ex-

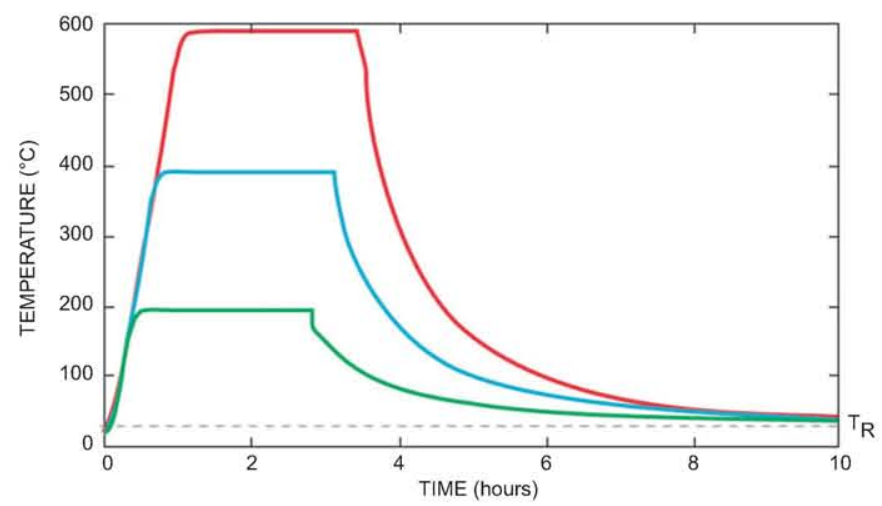

Fig. 7. Three fire scenarios: steel wires were heated in accordance with the temperature-time curves; tensile tests were performed after cooling

Table 4. Room temperature $\left(24^{\circ} \mathrm{C}\right)$ values after a simulated fire

\begin{tabular}{|c|c|c|c|c|c|c|}
\hline \multirow[t]{2}{*}{ Test conditions } & \multicolumn{2}{|c|}{$\sigma_{y}(\mathbf{M P a})$} & \multicolumn{2}{|c|}{$\sigma_{\max }(\mathrm{MPa})$} & $\varepsilon_{\max }(\%)$ & $\varepsilon_{r}(\%)$ \\
\hline & LS & HS & LS & HS & LS HS & LS HS \\
\hline & 1500 & & & & 4.75 .2 & 7.08 .4 \\
\hline $\left.\max 200^{\circ} \mathrm{C}\right)$ & 1495 & 1658 & 1854 & & 5.15 .3 & 6.67 .9 \\
\hline Fire b $\left(T_{\max } 400^{\circ} \mathrm{C}\right)$ & 1450 & 1563 & 1804 & 1962 & 5.25 .2 & 7.38 .7 \\
\hline Fire $\mathrm{c}\left(T_{\max } 600^{\circ} \mathrm{C}\right)$ & 1042 & 1181 & 1244 & 1415 & 5.66 .2 & 8.911 .4 \\
\hline
\end{tabular}

LS (low speed $\dot{\varepsilon}=10^{-3} \mathrm{~s}^{-1}$ ), HS (high speed $\dot{\varepsilon}=500 \mathrm{~s}^{-1}$ )

ample, testing conditions represent a conservative simulation because the duration of the fire is longer than the nominal fires [13-14]. The temperature was raised at a rate of $20^{\circ} \mathrm{C} / \mathrm{min}$ and the different maximum temperatures studied were 200,400 and $600^{\circ} \mathrm{C}$. After cooling, tensile tests at different strain rates were performed to obtain the residual mechanical properties of wires at room temperature TR. Test results are shown in Table 4.

For this particular example, it can be concluded that:

a) If the steel tendon does not exceed $200{ }^{\circ} \mathrm{C}$ during the fire, there is no appreciable effect on $\sigma_{y}$ and $\sigma_{\max }$ (differences are less than $0.02 \%$ ).

b) If the steel tendon reaches a temperature of $600{ }^{\circ} \mathrm{C}$ during the fire, its strength capacity decreases by about $30 \%$.

c) After a fire, static data $\left(\dot{\varepsilon}=10^{-3} \mathrm{~s}^{-1}\right)$ at room temperature are always lower than dynamic data $\left(\dot{\varepsilon}=500 \mathrm{~s}^{-1}\right)$ at room temperature.

Note that, as the prestressing force was neglected during the simulation, this particular example does not reproduce the whole thermomechanical history of the steel tendon. Even so, the authors [5] have shown that the most important factor influencing the mechanical damage is the maximum temperature reached during the fire. Consequently, these results provide a good appreciation of the steel behaviour.

\section{Comments and recommendations}

The response of structures under extreme conditions is sometimes a controversial and even emotive subject, for experts and also for those not so well informed. In this work, the effect of temperature and strain rate on the me- 

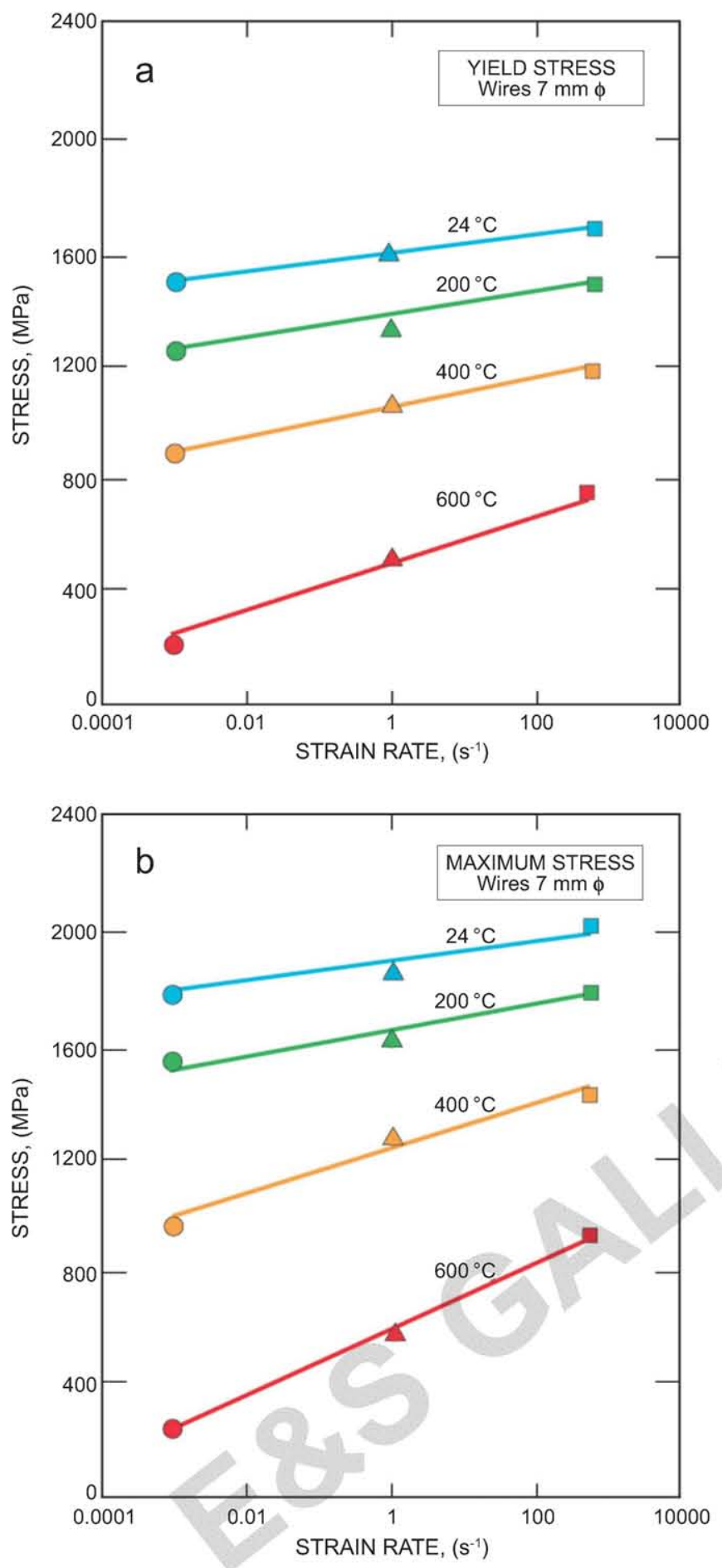

Fig. 8. Influence of strain rate on yield stress and tensile strength for different temperatures

chanical behaviour of prestressing steel wires has been characterized, in the hope that this information could be useful for engineers and designers when performing numerical modelling of prestressed concrete components under fire, explosions or impact loadings.

1. Behaviour at room temperature $\left(24^{\circ} \mathrm{C}\right)$

Experimental results show a mild increase of about $10 \%$ in the yield stress and maximum stress when the strain rate changes at almost six orders of magnitude (from $10^{-3}$ to $660 \mathrm{~s}^{-1}$ ). The Model Code (5.3.5.1) [9] states, as mentioned earlier, that "the tensile properties of prestressing
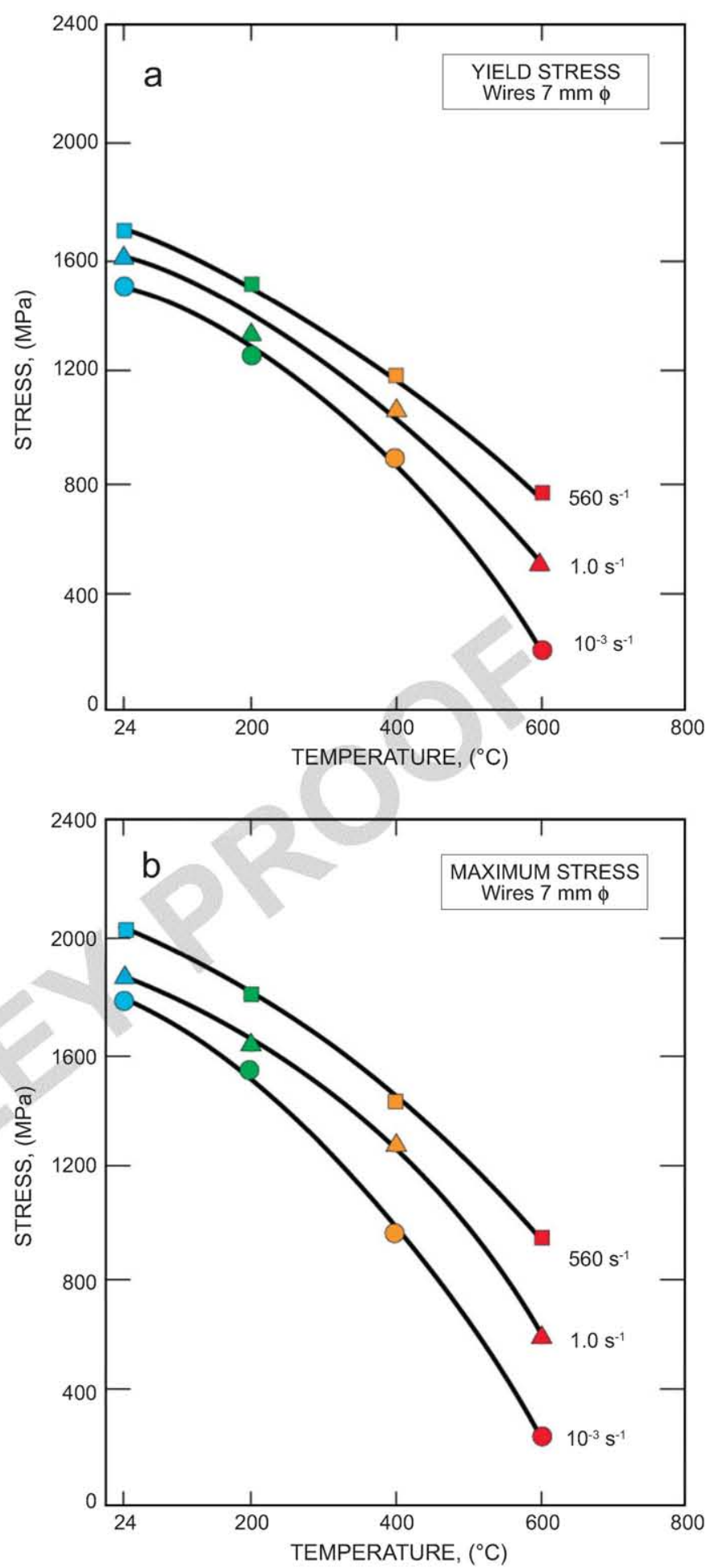

Fig. 9. Influence of temperature on yield stress and tensile strength for different strain rates

steel increase with speed or rate of strain application" without giving any figure. Hence, the use of static characteristic values (i.e. at $10^{-3} \mathrm{~s}^{-1}$ ) may be a safe option (see Figs. 8 and 9).

2. Behaviour at high temperatures and low strain rate tests (tests at $\dot{\varepsilon}=10^{-3} \mathrm{~s}^{-1}$ )

The mechanical properties decrease as the temperature increases. Experimental results agree quite well with recommended limits for design, as given in Eurocode 2 [13] 
and BS 8110 [14]. The use of simplified bilinear stressstrain curves for design purposes should take into account these effects. For temperatures up to $600^{\circ} \mathrm{C}$, the use of bilinear stress-strain curves based on the values shown in Table 2 (see Figs. 8 and 9) is recommended.

3. Behaviour at high temperatures and high strain rates An increase in temperature $\left(>200{ }^{\circ} \mathrm{C}\right)$ has a detrimental effect on the mechanical properties of steel wires. Even so, yield stress and maximum stress increase with strain rate when wires are tested at the same temperature. In this respect, in the event of data being unavailable for the right strain rate, using static values (i.e. at $\dot{\varepsilon}=10^{-3} \mathrm{~s}^{-1}$ ) for the temperature considered is a safe assumption (see Figs. 8 and 9).

4. Behaviour at room temperature after a simulated fire When steel tendons do not reach temperatures $>200^{\circ} \mathrm{C}$, no significant effect on yield stress or tensile strength need be considered. Otherwise, the behaviour of steel wires depends on the temperature-time history. What seems to happen (in the examples considered) is that a temperature-time history does not affect the performance regarding the influence of loading rate when wires are tested at room temperature, i.e. static values of yield stress and tensile strength at room temperature after a fire are always lower than dynamic ones, also at room temperature.

\section{Acknowledgements}

The authors are grateful to Dr.-Ing. Hans R. Ganz for suggesting the problem and for his helpful advice on the topic. Thanks are also due to Mr. Luís del Pozo and Mrs. Luisa Villar from EMESA Trefilería, S.A. (Arteixo, La Coruña, Spain) for the supply of the steel wires, as well as for their useful comments. The authors would also like to thank the Spanish Ministry of Science \& Innovi or financial support through the project with reference BIA2008-06705-C02-01.

\section{References}

1. Nakkalil, R., Hornaday, J. R., Bassim, M. N.: Characterization of the compression properties of rails steel in high temperatures and strain rates. Materials Science and Engineering A 141, 1991, pp. 247-260.

2. Itabashi, M., Kawata, K.: Carbon content effect on highstrain-rate tensile properties for carbon steels. International Journal of Impact Engineering 24, 2000, pp. 117-131.

3. He, S., van Houtte, P., van Bael, A., Mei, F., Sarban, A., Boesman, P., Gálvez, F., Atienza, J. M.: Strain rate effect in highspeed wire drawing process. Modelling and Simulation in Materials Science and Engineering 10, 2002, pp. 267-276.

4. Rohr, I., Nahme, H., Thoma, K.: Material characterization and constitutive modeling of ductile high-strength steel for a wide range of strain rates. International Journal of Impact Engineering 31, 2005, pp. 401-433.

5. Atienza, J. M., Elices, M.: Behavior of prestressing steels after a simulated fire: Fire-induced damages. Construction and Building Materials 23, 2009, pp. 2932-2940.

6. Johnson, G. R., Cook, W. H.: Fracture characteristics of three metals subjected to various strains, strain rates, temperatures and pressures. Engineering Fracture Mechanics 21, 1985, pp. 31-48.

7. Lin, Y. C., Chen, X., Liu, G.: A modified Johnson-Cook model for tensile behaviors of typical high-strength alloy steel. Materials Science and Engineering A 527, 2010, pp. 6980- 6986.

8. Concrete Structures under Impact and Impulsive Loading. CEB Bulletin 187, Comité Euro-international du Beton, Lausanne, Switzerland, 1988.

9. fib Bulletin 55, Model Code 2010, 1st draft.

10. Zukas, J. A., Nicholas, T., Swift, H. F., Greszczuk, L. B., Curran, D. R.: Impact Dynamics. Wiley, 1982.

11. Meyers, M. A.: Dynamic Behaviour of Materials. John Wiley \& Sons, NY, 1994.

12. Galvez, F., Cendón, D. A., Enfedaque, A., Sánchez-Gálvez, $V:$ : High strain rate and high temperature behaviour of metallic materials for jet engine turbine containment. Journal de Physique IV, 134, 2006, pp. 269-274.

13. Eurocode 2: Design of concrete structures - Part 1-2: General rules - Structural fire design. EN 1992-1-2: 2002, Feb 2005.

14. BS 8110: Structural use of concrete - Part 2: Code of practice for special circumstances. British Standards Institution, London, 1985.

15. ASTM Designation: Standard methods of fire tests of building construc' ' raterials. E119-88, ASTM Book of Standards, vol. 04.07, American Society for Testing \& Materials, 1988.

16. Working Partv 4 3-1: Fire design of concrete structures - Materials, structures and modelling. State-of-the-art report, fib Bulletin 38, Apr 2007.

17. Fire Design of Concrete Structures: CEB Bulletin 208, Comité Euro-international du Beton, Lausanne, Switzerland, 1991.

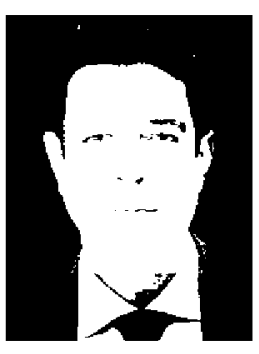

Manuel Elices melices@mater.upm.es

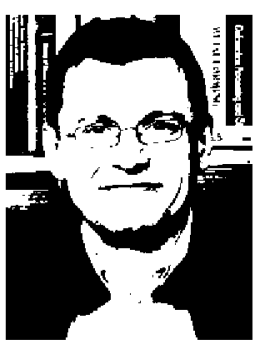

Jose Miguel Atienza jmatienza@mater.upm.es

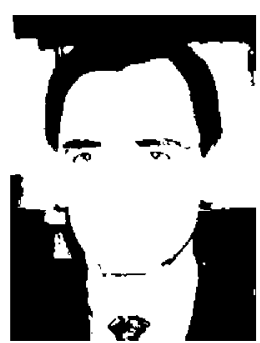

Francisco Gálvez jaime.galvez@mater.upm.es

Universidad Politécnica de Madrid Ciencia de Materiales, Madrid, Spain 